\title{
Associated factors to cervical dentin hypersensitivity in adults: a transversal study
}

\author{
Polyana Matos Alcântara, Nayara Franciele Figueiredo Barroso, Adriana Maria Botelho, \\ Dhelfeson Willya Douglas-de-Oliveira* (D), Patrícia Furtado Gonçalves and Olga Dumont Flecha
}

\begin{abstract}
Background: This cross-sectional study aimed to identify the factors associated to the cervical dentin hypersensitivity $(\mathrm{DH})$ in Brazilian adult population.

Methods: Three hundred and eighty patients (67.2\% women and 32.8\% men) were assessed by questionnaire and thermal test with ice. Participants marked in a visual analogue scale (VAS) the intensity of pain, and a calibrated examiner (ICC 0.990) measured the scores using a caliper. Pain scores above $0.5 \mathrm{~mm}$ were considered sensitive teeth. The DH associated factors were investigated by clinical examination. The association between variables was assessed by Spearman correlation and the Chi-square test. Logistic regression was used to determine the variables that predict $\mathrm{DH}(p<0.05)$.
\end{abstract}

Results: The mean age of participants was 24.08 years. In this population, 8958 teeth were evaluated, of those 3037 (33.9\%) were diagnosed sensitive. The most prevalent associated factors to DH were abnormal tooth positioning (9.0\%), occlusal trauma (6.5\%) and gingival recession (5.6\%). The erosion predicted significantly the DH on both simple (OR 7. $85, p<0.001)$ and multiple(OR 4.36, $p<0.001)$ analysis.

Conclusion: The exposure of dentinal tubules by erosion is probably the major predictor of dentin hypersensitivity. The healthy tooth is able to protect against $\mathrm{DH}$.

Keywords: Dentin hypersensitivity, Etiology, Diagnosis, Prevalence, Epidemiology

\section{Background}

The dentin hypersensitivity $(\mathrm{DH})$ is defined as an acute pain of short duration due exposure of dentin, in response to stimuli typically evaporative, osmotic (chemical) and tactile, that cannot be associated with any other form of dental defect or disease [1].

The most accepted theory for DH postulates that the fluids of the exposed canaliculi are disturbed by chemical or physical changes. Those changes and movements in the intratubular fluid stimulates baroreceptors which are present in pulp and within the dentin that lead to neural discharge, resulting in painful sensation [2].

The dentin is composed by canaliculi tubules that, under normal conditions, are isolated from the external

* Correspondence: dhelfeson@hotmail.com

Dentistry Departament, Federal University of Jequitinhonha and Mucuri

Valleys, Rua da Glória, 187, Centro, Diamantina, Minas Gerais 39100-000, Brazil environment by enamel or cementum. For the development of $\mathrm{DH}$, the dentin, along with their canaliculi, must become exposed to the oral cavity due to gingival recessions and/or loss of enamel/cementum by erosion, abrasion, attrition abfraction, or by incorrect oral hygiene technique [3].

The associated factors that lead to the dentin exposure into the oral cavity and subsequent DH (e.g., gingival recession and non-carious cervical lesions) are also under discussion, in other words, although many have been proposed, the main factors have not been established yet $[4,5]$.

The $\mathrm{DH}$ is a painful condition common in the adult population, its prevalence varies between 3 and $98 \%[5,6]$. This widely range can occurs due differences in sample, habits, dietaries, eligibility criteria and the diagnostic approaches used for each study [7].

The multifactorial aspect of $\mathrm{DH}$ need to be evaluated and to be determined in order to identify the factors

(C) The Author(s). 2018 Open Access This article is distributed under the terms of the Creative Commons Attribution 4.0 International License (http://creativecommons.org/licenses/by/4.0/), which permits unrestricted use, distribution, and 
causing DH [8]. The treatment of DH should be focused in decreasing or removing it causes and by using $\mathrm{DH}$ agents, professionally and/or personally (patient based) methods, to relieve discomfort $[7,9]$.

There is a lack of data on associated factors relating to this clinical condition among the Brazilian population. Therefore, this cross-sectional study aimed to identify the factors associated to the cervical dentin hypersensitivity.

\section{Methods}

\section{Study design}

This cross-sectional was approved by the Research Ethics Committee of Federal University of Jequitinhonha and Mucuri Valleys (UFVJM) under protocol number 092/ 2012. It was conducted at the Clinic of Oral Surgery and Periodontics of the Dentistry Department of UFVJM. It was performed according to the Helsinki Declaration of 1975, revised in 2013. All participants of this research have been instructed about the same and signed an informed consent prior the study.

\section{Sample}

The subjects were composed through a stratified sampling among students, professors and employees of UFVJM. It was included those who was older than 18 years, both genders, with good general health and agreed to participate in the research. It were excluded those patients who were undergoing treatment for dental bleaching, in order to avoid overestimation of $\mathrm{DH}$.

To determine the sample size, it was used the calculation for prevalence. It was used statistical significance level at $95 \%$ and margin of error set at 5\%. Prevalence $(33.8 \%)$ was obtained in the literature [10]. It resulted in 344 patients to be investigated. It was added $10 \%$ to the value to prevent losses. Then, the amount of participants was estimated at 378.

\section{Dentin hypersensitivity evaluation}

One examiner (PMA) was trained and calibrated by test-retest method for use of the caliper. The intraclass correlation coefficient was 0.990 .

It was performed clinical examination in order to identify the presence or not of the etiological factors related to $\mathrm{DH}$, and to dismiss pain related to any other tooth pathology. When the DH could not be related to any factor, it was considered "other factors" as etiologic factor. The clinical examination included thermal test which was run on all tooth that were: completelly erupted in the oral cavity, caries-free, restorations free and non-pillars.

In order to identify the DH in each teeth, a cold test was performed using an iced stick on the vestibular surface. The stimulus was maintained until the painful reaction of the volunteer, with a maximum time of $5 \mathrm{~s}$.
After the stimulus was applied, the participants were instructed to mark the pain intensity on a horizontal visual analogue scale (VAS) of $100 \mathrm{~mm}$, where the left and right edges were equivalents to "no pain" and "unbearable pain" respectively. Scores between 0 and $4 \mathrm{~mm}$ were considered as no pain; from 5 to $44 \mathrm{~mm}$, mild pain; from 45 to $74 \mathrm{~mm}$, moderate pain; and 75 to $100 \mathrm{~mm}$, severe pain [11]. An analog caliper was used to quantify the values of pain. For a tooth be considered as having $\mathrm{DH}$, it should respond to the cold test with a score equal to or greater than $5 \mathrm{~mm}$.

In cases of gingival recession, its height was measured. It was used Williams periodontal probe, the measurement was taken from the cement-enamel junction to the free gingival margin, in the middle of the vestibular surface.

The participants fulfilled a questionnaire created by the researches in order to identify the oral hygiene habits and previous DH treatment.

\section{Statistical analysis}

The collected data were analyzed by statistical software (Statistical Package for Social Sciences ${ }^{\circ}$ IBM Inc., USA) 23.0 version. Descriptive statistical analyses were carried out to obtain frequency, mean and standard deviation. The normality of the data was checked by the Kolmogorov-Sminorv test. The correlation between quantitative variables was done by Spearman correlation. Associations between categorical variables were estimated by the Chi-square test. It was adopted a significance level of $95 \%(p<0.05)$.

It was performed logistic regression in order to verify the odds ratio of associated factors that predicts $\mathrm{DH}$. In the non-adjusted regression, it were added the independent variables that obtained a $p$-value less than 0.05 in the Chi-Square test. For the adjusted model, it were selected the variables which had a $p$-value less than 0.05 in the simple regression and the confounding variables (age and sex). The model selection was based on an ascending stepwise procedure including variables to achieve the maximum Hosmer-Lemeshow goodness of fit.

\section{Results}

This research included 125 (32.8\%) men and 255 (67.2\%) women who contributed with 8958 tooth. The average age of the 380 participants was $24.08( \pm 7.17)$ years. Of the participants, 342 (90\%) reported being right-handed, 23 (5.7\%) left-handers and 15 (4.3\%) ambidextrous.

Forty-nine (12.9\%) participants had periodontal therapy in the last 6 months and 160 (42.0\%) subjects reported to use soft toothbrush. Sixty (15.8\%) patients had already treated the $\mathrm{DH}$, and $13(21.4 \%)$ reported no pain relieve (Table 1).

The amount of 3037 teeth was diagnosed as $\mathrm{DH}$ which represents prevalence of $33.9 \%$. The average pain in VAS was $47.3( \pm 27.5)$. The Table 2 shows the $\mathrm{DH}$ prevalence by teeth group. 
Table 1 Oral health care

\begin{tabular}{lll}
\hline & $\mathrm{n}$ & $\%$ \\
\hline Periodontal therapy (last 6 months) & & 12.9 \\
Yes & 49 & 87.1 \\
No & 331 & \\
Toothbrush bristles & & 1.6 \\
$\quad$ Extrasoft & 6 & 42.0 \\
Soft & 160 & 34.6 \\
Medium & 131 & 6.1 \\
Hard & 23 & 15.8 \\
$\quad$ Unknown & 60 & 15,8 \\
Dentin hypersensitivity treatment & & 84,2 \\
Yes & 60 & \\
No & 320 & 76,6 \\
Type of DH treatment $(n=60)$ & & 23,3 \\
In-home & 46 & 60,0 \\
In-office & 14 & 18,3 \\
Results of DH treatment $(n=60)$ & & 21,4 \\
Temporary relief & 36 & \\
Permanent relief & 11 & \\
No relief & 13 & \\
\hline
\end{tabular}

The etiologic factors most prevalent in hypersensitive teeth were abnormal tooth position $(9.0 \%)$, occlusal trauma (6.5\%) and gingival recession (5.6\%). Of the hypersensitivity tooth, 2124 (69.9\%) were healthy (Table 3 ).

The average of gingival recession height was $1.94 \mathrm{~mm}$ $( \pm 1.17)$. There was statistically significant correlation between $\mathrm{DH}$, gingival recession height, and age (Table 4).

There was statistically significant association between $\mathrm{DH}$ and: inflammation $(p=0.004)$, attrition $(p<0.001)$, other factors $(p=0.019)$, erosion $(p<0.001)$, bruxism $(p<0.001)$, gingival recession $(p<0.001)$, occlusal trauma $(p<0.001)$, abnormal tooth position $(p<0.001)$ and healthy tooth $(p<0.001)$ (Table 5)

Erosion, bruxism and gingival recession predicted significantly the dentin hypersensitivity, respectively, on both simple (OR 7.85 [4.67-13.19], $p<0.001$; OR 3.75 [2.535.58], $p<0.001$ and OR 3.67 [2.84-4.74], $p<0.001)$ and multiple (OR 4.36 [2.56-7.40], $p<0.001 ; 2.34$ [1.55-3.51], $p<0.001$; and OR 2.05 [1.55-2.70], $p<0.001)$ analysis

Table 2 Dentin hypersensitivity prevalence ( $n=3037$ tooth)

\begin{tabular}{lll}
\hline Tooth group & $\mathrm{n}$ & $\%$ \\
\hline Incisors & 1628 & 53.6 \\
Pre-molars & 773 & 25.5 \\
Canines & 525 & 17.3 \\
Molars & 111 & 3.7 \\
\hline
\end{tabular}

Table 3 Etiologic factors of dentin hypersensitivity ( $n=3037$ tooth)

\begin{tabular}{lll}
\hline Etiologic factor & $\mathrm{n}$ & $\%$ \\
\hline Abfraction & 3 & 0.1 \\
Atrition & 19 & 0.6 \\
Other factors & 41 & 1.4 \\
Erosion & 71 & 2.3 \\
Bruxism & 72 & 2.4 \\
Inflammation & 116 & 3.8 \\
Gingival recession & 170 & 5.6 \\
Occlusal trauma & 196 & 6.5 \\
Abnormal tooth position & 274 & 9.0 \\
Healthy & 2075 & 69.9 \\
\hline
\end{tabular}

(Table 6). The Hosmer-Lemeshow goodness of fit for the final adjusted model was 0.959 .

\section{Discussion}

The dentin hypersensitivity is a common clinical condition which presents several associated factors that should be considered in diagnosis and treatment $[12,13]$. The present observational study showed that the mainly $\mathrm{DH}$ associated factors involves loss of hard tissue leading to dentin exposure. According to Martens et al. (2013), for dentin exposure it is necessary loss of enamel or cementum exposure [14].

The most prevalent etiological factor was abnormal tooth positioning. The bad positioning, such as crowding of anterior teeth or orthodontic movement, repositions the teeth out of the correct dental arch position. This increases the risk of gingival recessions that can lead to dentin hypersensitivity [8]. Over more, the poorly positioned teeth are difficult to clean up which might causes plaque accumulation and periodontal complications like gingival inflammation and gingival recession. It should be noted that the presence of dental plaque increases the production of acids that demineralize the tooth surface that leads to the exposition of dentinal tubules to oral cavity [15].

The occlusal trauma was considered as etiological factor for DH in 196 teeth. This factor has been cited as responsible for deformation and dental movement, resulting in deflection of tooth structure, broken of enamel crystals in the cervical area and contributing to the exposure of coronal or cervical dentin $[8,16]$.

Table 4 Correlation between dentin hypersensitivity, gingival recession and age

\begin{tabular}{lll}
\hline & \multicolumn{2}{l}{ Dentin hypersensitivity } \\
\cline { 2 - 3 } & $r_{\mathrm{s}}$ & $p$ \\
\hline Gingival recession height & 0,147 & $<0,001$ \\
Age & $-0,025$ & 0,017 \\
\hline $\mathbf{r}_{\mathrm{s}}$ : Spearman correlation coeficient & &
\end{tabular}

$\mathrm{r}_{\mathrm{s}}$ : Spearman correlation coeficient 
Table 5 Association between etiologic factors and dentin hypersensitivity

\begin{tabular}{|c|c|c|c|}
\hline & \multicolumn{2}{|c|}{ Dentin Hypersensitivity } & \multirow[b]{2}{*}{$p$-value } \\
\hline & Present n (\%) & Absent n (\%) & \\
\hline \multicolumn{4}{|c|}{ Inflammation } \\
\hline Present & $116(3.8)$ & $161(2.7)$ & \multirow[t]{2}{*}{0.004} \\
\hline Absent & $2921(96.2)$ & $5760(97.3)$ & \\
\hline \multicolumn{4}{|l|}{ Abfraction } \\
\hline Present & $3(0.1)$ & $4(0.1)$ & \multirow[t]{2}{*}{0.617} \\
\hline Absent & 3034 (99.9) & 5917 (99.9) & \\
\hline \multicolumn{4}{|l|}{ Attrition } \\
\hline Present & $19(0.6)$ & $6(0.1)$ & \multirow[t]{2}{*}{$<0.001$} \\
\hline Absent & 3018 (99.4) & 5915 (99.9) & \\
\hline \multicolumn{4}{|l|}{ Erosion } \\
\hline Present & $71(2.3)$ & $18(0.3)$ & \multirow[t]{2}{*}{$<0.001$} \\
\hline Absent & $2966(97.7)$ & $5903(99.7)$ & \\
\hline \multicolumn{4}{|l|}{ Bruxism } \\
\hline Present & $72(2.4)$ & $38(0.6)$ & \multirow[t]{2}{*}{$<0.001$} \\
\hline Absent & 2965 (97.6) & $5883(99.4)$ & \\
\hline \multicolumn{4}{|c|}{ Gingival recession } \\
\hline Present & $170(5.6)$ & $94(1.6)$ & \multirow[t]{2}{*}{$<0.001$} \\
\hline Absent & $2867(94.4)$ & $5827(98.4)$ & \\
\hline \multicolumn{4}{|c|}{ Occlusal trauma } \\
\hline Present & $196(6.5)$ & $210(3.5)$ & \multirow[t]{2}{*}{$<0.001$} \\
\hline Absent & 2841 (93.5) & $5711(96.5)$ & \\
\hline \multicolumn{4}{|c|}{ Abnormal tooth position } \\
\hline Present & $274(9.0)$ & $374(6.3)$ & \multirow[t]{2}{*}{$<0.001$} \\
\hline Absent & $2763(91.0)$ & $5547(93.7)$ & \\
\hline \multicolumn{4}{|c|}{ Healthy tooth } \\
\hline Present & 2075 (69.9) & 5010 (84.6) & \multirow[t]{2}{*}{$<0.001$} \\
\hline Absent & $962(30.1)$ & $911(15.4)$ & \\
\hline \multicolumn{4}{|c|}{ Other factors } \\
\hline Present & $41(1.4)$ & $49(0.8)$ & \multirow[t]{2}{*}{0.019} \\
\hline Absent & 2996 (98.6) & $5872(99.2)$ & \\
\hline \multicolumn{4}{|l|}{ Quadrant } \\
\hline First & $829(27.3)$ & 1413 (23.9) & \multirow[t]{4}{*}{0.107} \\
\hline Second & $740(24.4)$ & 1514 (25.6) & \\
\hline Third & 809 (26.6) & $1423(24.0)$ & \\
\hline Fourth & $659(21.7)$ & $1571(26.5)$ & \\
\hline
\end{tabular}

Chi-square test

An amount of 170 teeth was associated with gingival recession, being the third most prevalent etiological factor in the present study. However, several studies pointed the gingival recession as the main etiologic factor for $\mathrm{DH}[17,18,20]$. Once the root and cementum surface is displayed, they are quickly lost by brushing and/or
Table 6 Logistic regression of the factors that predicts the dentin hypersensitivity

\begin{tabular}{|c|c|c|c|c|}
\hline \multirow[t]{2}{*}{ Variable } & \multicolumn{2}{|l|}{ Non-adjusted } & \multicolumn{2}{|l|}{ Adjusted } \\
\hline & OR (Cl 95\%) & $p$-value & OR (Cl 95\%) & $p$-value \\
\hline \multicolumn{3}{|c|}{ Inflammation } & \multicolumn{2}{|l|}{-} \\
\hline Absent & 1 & & & \\
\hline Present & $1.42(1.11-1.81)$ & 0.005 & & \\
\hline \multicolumn{3}{|l|}{ Abfraction } & \multicolumn{2}{|l|}{-} \\
\hline Absent & 1 & & & \\
\hline Present & $1.46(0.32-6.53)$ & 0.619 & & \\
\hline \multicolumn{5}{|l|}{ Attrition } \\
\hline Absent & 1 & & 1 & \\
\hline Present & $6.20(2.47-15.56)$ & $<0.001$ & $3.61(1.42-9.13)$ & 0.007 \\
\hline \multicolumn{5}{|l|}{ Erosion } \\
\hline Absent & 1 & & 1 & \\
\hline Present & $7.85(4.67-13.19)$ & $<0.001$ & $4.36(2.56-7.40)$ & $<0.001$ \\
\hline \multicolumn{5}{|l|}{ Bruxism } \\
\hline Absent & 1 & & 1 & \\
\hline Present & $3.75(2.53-5.58)$ & $<0.001$ & $2.34(1.55-3.51)$ & $<0.001$ \\
\hline
\end{tabular}

Gingival recession

$\begin{array}{cllll}\text { Absent } & 1 & 1 & \\ \text { Present } & 3.67(2.84-4.74) & <0.001 & 2.05(1.55-2.70) & <0.001\end{array}$

professional cleaning, exposing the dentin tubules [8]. There was a weak statistically significant positive correlation between height of the gingival recession and pain score in the ice test, suggesting that higher the dentin exposed area, greater the response to stimuli and greater the DH pain. 
There was a weak statistically significant negative correlation between age and $\mathrm{DH}$. This result disagrees to previous studies that found a greater prevalence of hypersensitivity in the age range of 36-45 [11], 40-49 [21] and 50-59 [10]. However, the present finding corroborates with several researches that found higher prevalence in 20-39 years-old [22, 23]. The differences in the distribution of $\mathrm{DH}$ according to age can be due the profile of populations of each study. The negative correlation may also be understand as age-related changes in dentin-pulp complex: the dentin sclerosis and the establishment of secondary and tertiary dentin may be responsible for the decrease in the presence and/or pain level of $\mathrm{DH}$, once the dentin permeability and its the hydraulic conductance is reduced [15, 24].

The erosion was able to predict the DH in both simple and multiple regression, being the factor with biggest odds ratio. The teeth with erosion has odds of 4.36 to have DH in comparison to those with no erosion, independently of other conditions such as age, sex and presence of gingival recession. The present result corroborate the literature which reported that the importance of erosion has become more evident as the main risk factor for DH over recent years [9]. Erosion starts by make softer the plaque-free tooth surface, then, it is followed by constant layer-by-layer dissolution leading to permanent loss of tooth hard tissue with the outer layer soften [12]. This situation allow the dentinal tubules to be patent from the pulp to the oral environment, thereby causing $\mathrm{DH}$.

A great amount of tooth with DH had no associated factors, in these cases, the tooth was considered to be healthy, and the $\mathrm{DH}$ was attributed to a failure in cemento-enamel junction (CEJ) [25]. The CEJ morphology may present in three ways: cememtum overlapped the enamel; edge-t-edge relationship between cementum and enamel; and, cementum and enamel fail to meet [26]. This third relationship leads to exposure dentin, which may result in $\mathrm{DH}$.

Also, the great majority of the total investigated teeth was considered healthy and had no DH. The logistic regression showed the healthy tooth as a protective factor against the $\mathrm{DH}$. This finding is in accordance with the hydrodynamic theory [2]. The DH occurs in situations that the dentin become exposed to the oral cavity with open dentinal tubules which provide a direct link between the oral environment and the internal pulp of the tooth [13]. When the exposed dentin contacts with externally stimuli, painful sensations can arise [8]. The protective capable of healthy tooth herein proposed is based on the integrity of the enamel that inhibits the external agents to stimuli the intratubular fluid. However, some tooth may present $\mathrm{DH}$ even with no associated factors, in this cases, the DH in healthy tooth can be attributed to a failure in cemento-enamel junction that leads to exposure dentin [25].
The tooth groups most affected by DH teeth were incisors and premolars. Several studies pointed out incisors as most prevalent for presenting a greater wear and loss of enamel and dentin, and for displaying little enamel thick when compared to other tooth groups [8, 27, 28]. In general, teeth most commonly affected are premolars in the adult population $[17,19,29]$, due its positioning in the dental arch. They are more likely to be brushed with excessive force, consequently, more disposed to gingival recession and loss of hard tissue [30].

In the future, a growing number of people can be affected by injuries predisposing to dental hypersensitivity due the increasing in longevity and maintenance of teeth in healthy condition [12, 13]. This will bring clinical importance to research new forms of treatment and effective products of easy access. It is of great relevance studies that identify the prevalence and factors associated with this painful condition, since the choice of appropriate treatment depends on a clear conception of the $\mathrm{DH}$ by the clinicians [20,30]. It is important to note that the present data showed that $81.4 \%$ of the $\mathrm{DH}$ treatment failed which may indicates a recurrent condition. This fact may be explained by the episodic phenome of DH [31,32].

Hanneet et al. (2016) [8], concluded that it is important to identify the aetiology behind $\mathrm{DH}$, and minimise these contributory factors before formulating treatment strategies. An increase in the understanding of the associate factors involved in dentin hypersensitivity is essential for the development of the clinical management of this condition. Such information could be harvested from epidemiological and interventional studies.

\section{Conclusion}

It can be concluded that incisors are the teeth most affected by DH. The exposure of dentinal tubules by erosion is probably the major predictor of dentin hypersensitivity. The teeth with erosion like to have 4.36 more odds to have DH than teeth without erosion. The healthy tooth is able to protect against $\mathrm{DH}$. Clinician should be able to treat and to manage the $\mathrm{DH}$ for a better and lasting relief of pain.

\section{Abbreviations \\ DH: Dentin Hypersensitivity; OR: Odds Ratio; UFVJM: Federal University of Jequitinhonha and Mucuri Valleys; VAS: Visual Analogue Scale \\ Acknowledgements \\ The authors thank National Council for Scientific and Technological Development (CNPq), agency of the Ministry of Science, Technology, Innovation and Communications (MCTIC), for scholarships received from Scientific Initiation program.}

Funding

This study was supported by the researchers.

Availability of data and materials

The datasets used and analyzed during the current study are available from the corresponding author on reasonable request. 


\section{Key findings}

The erosion is the major associated factor to dentin hypersensitivity (DH). The healthy tooth is protective against $\mathrm{DH}$.

\section{Authors contributions}

PMA, NFFB, AMB, DWDO, PFG and ODF designed the study. PMA and NFFB acquired the data. DWDO performed statistical analyses. All authors analysed and interpreted the data. PMA and NFFB drafted the manuscript under the supervision of AMB, DWDO, PFG and ODF. All authors have read and approved the final manuscript

\section{Ethics approval and consent to participate}

This study was approved by the Research Ethics Committee of Federal University of Jequitinhonha and Mucuri Valleys (UFVJM) under protocol number 092/2012. It was performed according to the Helsinki Declaration of 1975, revised in 2013. All participants of this research have been instructed about the same and signed an informed consent prior the study.

\section{Consent for publication}

Not applicable.

\section{Competing interests}

The authors declare that they have no competing interests.

\section{Publisher's Note}

Springer Nature remains neutral with regard to jurisdictional claims in published maps and institutional affiliations.

Received: 1 March 2018 Accepted: 16 August 2018

Published online: 03 September 2018

\section{References}

1. Addy M, Mostafa P, Absi EG, Adams D. Cervical dentin hypersensitivity. Etiology and management with particular reference to dentifrices. In: Rowe $\mathrm{NH}$, editor. Proceedings of symposium on hypersensitive dentin origin and management. Michigan: University of Michigan; 1985. p. 147-67.

2. Brännström M Åström MD. The hydrodynamics of the dentin: it's possible relationship to dentinal pain. Int Dent J. 1972;22:219-27.

3. Jacobsen PL, Bruce G. Clinical dentin hypersensitivity: understanding the causes and prescribing a treatment. J Contemp Dent Pract. 2001;2:1-8.

4. Gillam DG, Seo HS, Bulman JS, et al. Perceptions of dentine hypersensitivity in a general practice population. J Oral Rehabil. 1999:26:710-4.

5. West NX, Sanz M, Lussi A, et al. Prevalence of dentine hypersensitivity and study of associated factors: a European population-based cross-sectional study. J Dent. 2013;41:841-51

6. Flynn J, Galloway R, Orchardson R. The incidence of hypersensitive teeth in the west of Scotland. J Dent. 1985;13:230-6.

7. Davari A, Ataei E, Assarzadeh H. Dentin hypersensitivity: etiology, diagnosis and treatment; a literature review. J Dent (Shiraz). 2013;14:136-45.

8. Haneet RK, Vandana LK. Prevalence of dentinal hypersensitivity and study of associated factors: a cross-sectional study based on the general dental population of Davangere. Karnataka. India. Int Dent J. 2016:66:49-57.

9. West N, Seong J, Davies M. Dentine hypersensitivity. Monogr Oral Sci. 2014;25:108-22.

10. Oderinu OH, Savage KO, Uti OG, Adegbulugbe IC. Prevalence of selfreported hypersensitive teeth among a group of Nigerian undergraduate students. Niger Postgrad Med J. 2011;18:205-9.

11. Jensen MP, Chen C, Brugger AM. Interpretation of visual analog scale ratings and change scores: a reanalysis of two clinical trials of postoperative pain. J Pain. 2003:4:407-14.

12. West NX, Lussi A, Seong J, Hellwig E. Dentin hypersensitivity: pain mechanisms and aetiology of exposed cervical dentin. Clin Oral Investig 2013;1:S9-19.

13. Bartold PM. Dentinal hypersensitivity: a review. Aust Dent J. 2006;51:212-8.

14. Martens LC. A decision tree for the management of exposed cervical dentin (ECD) and dentin hypersensitivity (DHS). Clin Oral Investig. 2013;1:S77-83.

15. Suge T, Kawasaki A, Ishikawa K, Matsuo T, Ebisu S. Effects of plaque control on the patency of dentinal tubules: an in vivo study in beagle dogs. J Periodontol. 2006;77:454-9.

16. Litonjua LA Andreana S, Bush PJ, Tobias TS, Cohen RE. Noncarious cervical lesions and abfractions: a re-evaluation. J Am Dent Assoc. 2003;134:845-50.
17. Amarasena N, Spencer J, Ou Y, Brennan D. Dentine hypersensitivity in a private practice patient population in Australia. J Oral Rehabil. 2011; https://doi.org/10.1111/j.1365-2842.2010.02132.x.

18. Rahiotis C, Polychronopoulou A, Tsiklakis K, Kakaboura A. Cervical dentin hypersensitivity: a cross sectional investigation in Athens, Greece. J Oral Rehabil. 2013;38:52-60.

19. Bahsi E, Dalli M, Uzgur R, Turkal M, Hamidi MM, Colak H. An analysis of the aetiology, prevalence and clinical features of dentine hypersensitivity in a general dental population. Eur Rev Med Pharmacol Sci. 2012;16:1107-16.

20. Flecha OD, Azevedo CG, Matos FR, Vieira-Barbosa NM, Ramos-Jorge ML, Gonçalves PF, Koga Silva EM. Cyanoacrylate versus laser in the treatment of dentin hypersensitivity: a controlled, randomized, double-masked and non-inferiority clinical trial. J Periodontol. 2013:84:287-94.

21. Ye W, Feng XP, Li R. The prevalence of dentine hypersensitivity in Chinese adults. J Oral Rehabil. 2012;39:182-7.

22. Al-Khafaji $\mathrm{H}$. Observations on dentine hypersensitivity in general dental practices in the United Arab Emirates. Eur J Dent. 2013;7:389-94.

23. Orchardson R, Collins WJN. Clinical features of "hypersensitive" (HS) dentine. J Dent Res. 1984;63:521.

24. Vandana KL, Haneet RK. Cementoenamel junction: an insight. J Indian Soc Periodontol. 2014;18:549-54.

25. Naidu GM, Ram KC, Sirisha NR, Sree YS, Kopuri RK, Satti NR, Thatimatla C. Prevalence of dentin hypersensitivity and related factors among adult patients visiting a dental School in Andhra Pradesh, southern India. J Clin Diagn Res. 2014;8:ZC48-51.

26. Arambawatta K, Peiris R, Nanayakkara D. Morphology of the cementoenamel junction in premolar teeth. J Oral Sci. 2009;51:623-7.

27. Michael JA, Townsend GC, Greewood LF, Kaidonis JA. Abfraction: separating fact from fiction. Aust Dent J Rehabil. 2009:54:2-8.

28. Zhang Y, Cheng R, Cheng G, Zhang X. Prevalence of dentine hypersensitivity in Chinese rural adults with dental fluorosis. J Oral Rehabili. 2014:41:289-95

29. Liu B, Zhang M, Chen Y, Yao Y. Tooth wear in aging people: an investigation of the prevalence and the influential factors of incisal/occlusal tooth wear in Northwest China. BMC Oral Health. 2014;14:65.

30. Cunha-Cruz J, Wataha JC, Heaton LJ Rothen M, Sobieraj M, Scott J, Berg J. The prevalence of dentin hypersensitivity in general dental practices in the Northwest United States. J Am Dent Assoc. 2013;144:288-96.

31. Olley RC, Moazzez R, Bartlett D. The relationship between incisal/occlusal wear, dentine hypersensitivity and time after the last acid exposure in vivo. J Dent. 2015:43:248-52.

32. Pashley $\mathrm{DH}$. How can sensitive dentine become hypersensitive and can it be reversed? J, vol. 41: Dent; 2013. p. S49-55.

Ready to submit your research? Choose BMC and benefit from:

- fast, convenient online submission

- thorough peer review by experienced researchers in your field

- rapid publication on acceptance

- support for research data, including large and complex data types

- gold Open Access which fosters wider collaboration and increased citations

- maximum visibility for your research: over $100 \mathrm{M}$ website views per year

At BMC, research is always in progress.

Learn more biomedcentral.com/submissions 